\title{
A P4P model for increased utilization of maternal, newborn and child health services in Bangladesh
}

Md. Noorunnabi Talukder

Ubaidur Rob

Population Council

Laila Rahman

Population Council

Ismat Ara Hena

A.K.M. Zafar Ullah Khan

Follow this and additional works at: https://knowledgecommons.popcouncil.org/departments_sbsr-rh

Part of the Demography, Population, and Ecology Commons, Family, Life Course, and Society Commons, International Public Health Commons, and the Medicine and Health Commons How does access to this work benefit you? Let us know!

\section{Recommended Citation}

Talukder, Md. Noorunnabi, Ubaidur Rob, Laila Rahman, Ismat Ara Hena, and A.K.M. Zafar Ullah Khan. 2011. "A P4P model for increased utilization of maternal, newborn and child health services in Bangladesh." Dhaka: Population Council. 
POLICY

BRIEF

DECEMBER 2011
A P4P MODEL FOR INCREASED UTILIZATION OF MATERNAL, NEWBORN AND CHILD HEALTH SERVICES IN BANGLADESH

\section{INTRODUCTION}

Maternal health programs are yet to yield desired impact on the utilization of obstetric care services from facilities in Bangladesh. Most deliveries are conducted by untrained persons at home, demonstrating the inequity in the access of women to required maternal health care services and the underutilization of the existing capacity for obstetric and newborn care services. Sub-optimal performance of service providers is a key barrier to improve availability and quality of maternal, newborn, and child health (MNCH) services. For increasing utilization of $\mathrm{MNCH}$ services from facilities for contributing to Millennium Development Goals (MDGs) 4 and 5, an operations research study on pay-for-performance (P4P) for providers with subsidized consumer-cost approach was initiated in February 2010.

The study was a part of Government of BangladeshUnited Nations $\mathrm{MNCH}$ and maternal and newborn health $(\mathrm{MNH})$ projects. The study has been included as a human resource innovation project under the operational plan of the Directorate General of Health Services (DGHS), Ministry of Health and Family Welfare (MOHFW), Government of Bangladesh. Population Council provided technical assistance to the DGHS in implementing the study. James P. Grant School of Public Health of BRAC University collaborated with Population Council in the study.

This policy brief describes the implementation of P4P operations research study and its consequent implications for policymakers.

\section{STUDY LOCATION}

P4P project was implemented in three districts. As the study was nested within existing $\mathrm{MNCH} / \mathrm{MNH}$ projects, three districts were purposively selected for intervention. The selected districts were Gaibandha, Kurigram and Jamalpur. Four facilities from each district - one District Hospital and three Upazila Health Complexes (UHCs) - were exposed to the interventions. From three districts, 12 government health facilities were the intervention sites while four facilities in another district comprised of the control site. Thakurgaon, an $\mathrm{MNH}$ intervention district, was selected as the control site. The experimental groups received the program interventions for 14 months.

\begin{tabular}{lll}
\multicolumn{2}{c}{ P4P scheme implementing facilities } \\
\hline Gaibandha & Kurigram & Jamalpur \\
\hline District & District & District \\
Hospital & Hospital & Hospital \\
Sunderganj & Nageshwari & Islampur \\
UHC & UHC & UHC \\
Fulchhari & Bhurungamari & Melandah \\
UHC & UHC & UHC \\
Shaghata & Chilmari UHC & Bakshiganj \\
UHC & & UHC \\
\hline
\end{tabular}

\section{STUDY DESIGN}

P4P project tested the feasibility of performancebased invectives, that is, paying an incentive to the institution based on certain performance targets achieved by the facility as a whole, provided that the minimum required facility infrastructure including human resources is in place.

Two strategies were tested across study sites. The 'first strategy' was a combination of payfor-performance and demand-side-financing while the 'second strategy' employed only pay-for-performance. Specifically, the first strategy introduced a P4P scheme for motivating service providers to improve the quantity as well as the quality of services and enabled poor pregnant women, and poor mothers of newborns and under-five children to access services 
by reducing their out-of-pocket costs. The second strategy constituted a P4P scheme for providers only.

Among three intervention districts, two districts (Gaibandha and Kurigram) implemented the Strategy 1 with incentives for both providers and clients while the other district (Jamalpur) tested Strategy 2 with the provision of incentive to providers only.

To measure the impact of interventions, data were collected through service statistics, exit surveys among the eligible women, in-depth interviews with service providers, and visits of "quality assurance group".

\section{IMPLEMENTATION OF THE PROJECT}

The project was implemented in two phases: preparatory or development, and implementation.

\section{A. Preparatory Phase}

Prerequisites to initiate P4P scheme

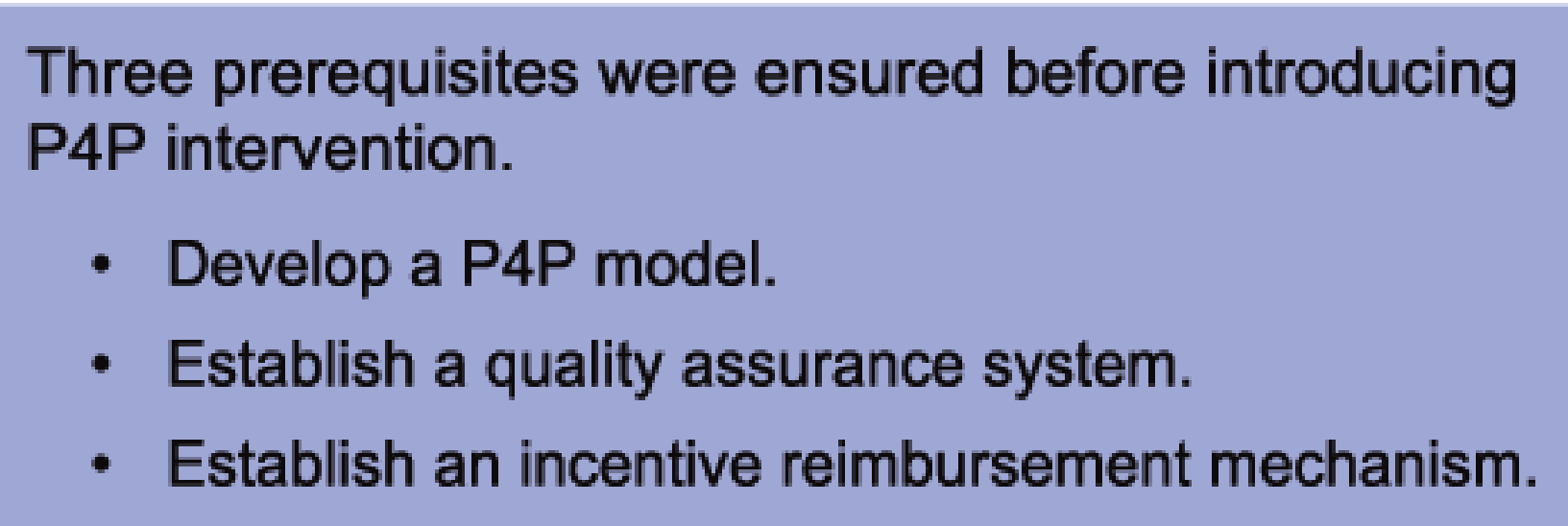

(i) Develop a P4P model. Development of an implementable P4P model with defined guidelines was the first and foremost task of the study. Pay-for-Performance Guidelines were developed based on the national and local level consensus building workshops with program managers and professional bodies and literature reviews, and approved by DGHS. The mechanism for implementing and monitoring P4P initiatives into the government health system is delineated in those guidelines.

(ii) Establish a quality assurance system. Prior to introducing P4P approach, health facilities must remain functional with necessary infrastructure, human resources, and logistics and supplies, for which an in-built quality assurance system was established with broadly two purposes: accredit the facilities that provide minimum acceptable level of $\mathrm{MNCH}$ care; and ensure routine assessment of performance of the facility. (iii) Establish an incentive reimbursement mechanism. Establishing an incentive payment mechanism was the last condition to meet before introducing P4P. A systematic financial reimbursement mechanism was developed for calculating and verifying incentives. Calculation of the amount of incentives payable to the service providers remained with the project staff. Payment mechanism used in the P4P project included a mixed system with bank transfer for provider incentive and cash payment for clients. An audit firm was employed to validate the incentive payment related to performance and the disbursement of fund.

Setting the stage for improved teamwork and referral

Promoting teamwork. Quality of care and utilization of $\mathrm{MNCH}$ services depend on well-coordinated teams at the health facility. P4P is a pioneer project in Bangladesh where incentive (based on quantity and quality of services) was provided to manager, direct and indirect service providers, and administrative and support staff in order to strengthen $\mathrm{MNCH}$ services, where team work is a prerequisite.

At each facility, there were team-building workshops to revitalize the work-team spirit. Staff members were sensitized to acknowledge the significance of the role of each other despite having different skills and expertise. These workshops also enabled the team members to assess the existing work environment and explore the dynamics of teamwork along with the leadership mechanism at both facility level and service unit level.

Within the facility, the $\mathrm{MNCH}$ team was divided into smaller teams or service units to provide specific services. Quality Assurance Teams (QATs) were formed for the following units: emergency room, labor room, Operation Theater, autoclave room, female ward, child ward or newborn care corner, pharmacy, store, laboratory, antenatal and postnatal care corner, and family planning corner. For each of the QATs, a leader was identified and given responsibility to coordinate the activities of the respective unit. QATs were to monitor and review service performance fortnightly and ensure coordination between team members.

Strengthening referral system. Absence of a systematic referral mechanism was one of the reasons for underutilization of health facilities. Referral system was strengthened through ensuring coordination between three types of fieldworkers (Health Assistants, Family Welfare Assistants and NGO fieldworkers) and providing referral incentive. There were workshops to orient the fieldworkers on the 
referral mechanism proposed under P4P project and to work in coordination for avoiding duplication of referrals. Incentives were given to fieldworkers against the individual referral cases.

\section{Creating a platform for improved management}

Institution-based P4P Committees were constituted to implement, oversee, facilitate and manage the P4P project activities. A six-member P4P Committee was formed for each of the District Hospitals and Upazila Health Complexes.

\section{District Hospital P4P Committee \\ - Civil Surgeon: Chairperson \\ - Deputy Director-Family Planning: Member \\ - Nursing Superintendent: Member \\ - BRAC/CARE representative: Member \\ - Bangladesh Medical Association (BMA) representative: Member \\ - RMO: Member-Secretary \\ Upazila Health Complex P4P Committee \\ - UHFPO: Chairperson \\ - Upazila Family Planning Officer: Member \\ - Nursing Supervisor: Member \\ - BRAC/CARE representative: Member \\ - Upazila Parishad representative: Member \\ - RMO: Member-Secretary}

UHFPO = Upazila Health and Family Planning Officer RMO $=$ Resident Medical Officer

Monthly meeting was in-built in the functioning of P4P Committee, which provided a platform to review the performance of the facility, and take appropriate measures, as necessary. Other key responsibilities of P4P Committees included setting benchmark and performance targets and managing incentive distribution.

As part of the financial management under P4P project, the committees were mandated to receive the incentive fund and the "drugs, consumables and maintenance" fund (certain amount of money for meeting expenses for shortfall in essential drugs, consumables, and maintenance) in the P4P Committee's bank account, keep appropriate records, and approve of incentive distribution to the beneficiaries.

\section{B. Intervention Phase}

Incentive scheme was in effect from October 2010 through November 2011. The key activities of the intervention phase included: introducing quality assurance; and providing financial incentives to service providers under the P4P mechanism.

\section{Introducing quality assurance}

Quality Assurance Groups (QAGs) have been formed for each of the study facilities, consisting of specialists from nearby Medical College Hospital or District Hospital and representative of professional body, with the purpose to provide systematic visits to health facilities to accredit and assess. QAGs made quarterly visits to the facilities to assess their performance in terms of quantity and quality of care as well as to provide supportive feedback to the providers in improving maternal, newborn and child health services.

In its quarterly visit, Quality Assurance Group reviewed the quantitative performance and provided judgments to the P4P Committee to set their performance targets. However, measuring performance achievements and determining eligibility for incentive were exclusively remained with the QAG. QAG assessments were used in calculating performance measurement for payment of incentive.

\section{QAG for District Hospital}

- Civil Surgeon: Convener

- Faculty, Gynecology/Obstetrics, Medical College

- Faculty, Anesthesiology, Medical College

- Faculty, Pediatrics, Medical College

- District Representative, Obstetrical and Gynecological Society of Bangladesh

- Representative, Implementing agency

QAG for comprehensive EOC Upazila Health Complex - UHFPO: Convener

- Faculty, Gynecology/Obstetrics, Medical College

- Faculty, Anesthesiology, Medical College

- Faculty, Pediatrics, Medical College

- Representative, Implementing agency

\section{QAG for basic EOC Upazila Health Complex}

- UHFPO: Convener

- Consultant, Gynecology/Obstetrics, District Hospital

- Consultant, Pediatrics, District Hospital

- Representative, Implementing agency 
Implementing a P4P mechanism

The process and structure to pay incentives to service providers and recipients are discussed below.

- Incentive recipients. Incentives were provided to motivate service providers at the institution level. The main thrust of introducing P4P approach was to increase institutional deliveries, where managers, direct and indirect service providers related to $\mathrm{MNCH}$ care and administrative and support staff were entitled to receive incentive if the performance targets were achieved or exceeded. Provider performance was linked with both quantity and quality of services.

- Performance targets. Quarterly targets for $\mathrm{MNCH}$ services were set for the institution as a whole, which took into account both quantity and quality of services. Two levels of quantitative performance targets based on the benchmark were set to pay incentives to the health facility. Amount of incentive for a facility varied according to its level of performance improvement - higher incentive payment for higher performance improvement.

The incentive was paid on quarterly basis; and the facility-based providers earned at least one-month basic salary in a quarter if the facility attained the first level of target. In case of achieving the second level of target, the providers received one and a half month's basic salary in a quarter.

Incentives payable to providers and staff were calculated on the basis of level of efforts; for instance, managers and direct service providers received full incentive while indirect service providers and administrative staff received half incentive. Performance of a facility was measured using service statistics and QAG visit reports.

- Reimbursement mechanism for providing incentives. A systematic financial reimbursement system was employed for calculating, disbursing and verifying incentives. At the end of each quarter, performance was measured and the level of incentives was determined. Incentive payment related to performance was determined by the QAG teams, and reimbursed by the project implementing agency. The project staff calculated the amount of incentives payable to the service providers by using the QAG visit report and analyzing service statistics. Service providers received incentive quarterly for achieving the facility-based performance targets. An audit firm validated the disbursement of fund and cross-checked the exposure of clients to the interventions.

\section{Functioning of P4P Mechanism}

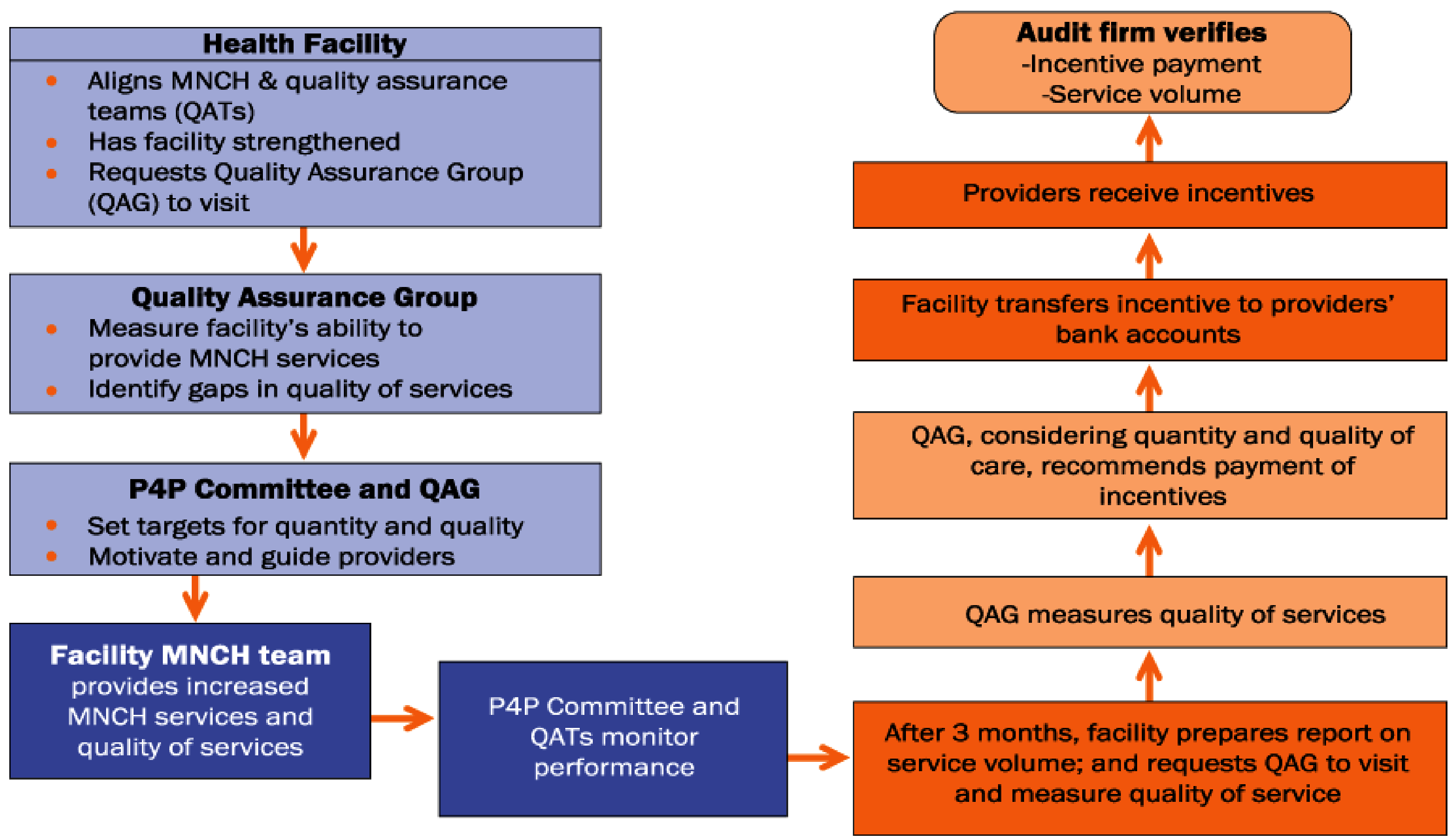


- Reaching poor clients. Coupons were provided to cover transportation, medicines, and incidental costs relating to unforeseen expenses that $\mathrm{MNCH}$ service recipients incurred while staying at a facility. Medicines were provided on receipt of a medicine coupon, while cash was provided to beneficiaries to meet transportation and incidental costs after receiving services. Poor pregnant women and poor mothers of newborns and under-five children in the project areas in Gaibandha and Kurigram districts received the financial assistance.

\section{FINDINGS}

$\mathrm{P} 4 \mathrm{P}$ project is a human resource innovation initiative paying financial incentive to the institution for achieving pre-determined performance targets. This performance-based incentive was implemented in 12 public-sector health facilities (9 Upazila Health Complexes and 3 District Hospitals) for five quarters. Assessment of the performance indicates that in 93 percent of cases, facilities received incentives based on achieving both the quantity and quality targets (Table 1).

Table 1. Number of facilities achieving incentives by quarter

\begin{tabular}{lcccccc}
\hline $\begin{array}{l}\text { Incen- } \\
\text { tive }\end{array}$ & $\begin{array}{c}\text { Oct- } \\
\text { Dec } \\
\text { status }\end{array}$ & $\begin{array}{c}\text { Jan- } \\
\text { Mar } \\
\text { '11 }\end{array}$ & $\begin{array}{c}\text { Apr- } \\
\text { Jun } \\
\text { '11 }\end{array}$ & $\begin{array}{c}\text { Jul- } \\
\text { Sep } \\
\text { '11 }\end{array}$ & $\begin{array}{c}\text { Oct- } \\
\text { Dec } \\
\text { '11 }\end{array}$ & $\begin{array}{c}\% \\
\text { re- } \\
\text { incen- } \\
\text { tives }\end{array}$ \\
\hline Achieved & 11 & 11 & 12 & 11 & 11 & $93 \%$ \\
$\begin{array}{l}\text { Could } \\
\text { not } \\
\text { achieve }\end{array}$ & 1 & 1 & - & 1 & 1 & $7 \%$ \\
$\begin{array}{l}\text { Total } \\
\text { facilities }\end{array}$ & 12 & 12 & 12 & 12 & 12 & $100 \%$ \\
\hline
\end{tabular}

Due to the P4P interventions, service volume increased remarkably at the Upazila Health Complexes (Figure 1). However, there was a variation in increase, which was primarily due to the number of beds at the facilities and physical accessibility. Prior to the P4P interventions, all facilities except one used to conduct 30 deliveries or less in a quarter. During the intervention period, five facilities (Chilmari, Bakshiganj, Sunderganj, Islampur and Nageshwari Upazila Health Complexes) conducted roughly 90 deliveries per quarter although the availability of human resources was in the poorest condition at
Chilmari Upazila Health Complex (only three doctors including UHFPO and RMO) and Bakshiganj Upazila Health Complex (only four doctors including UHFPO and RMO).

Figure 1. Changes in quarterly performance of institutional delivery at Upazila Health Complexes

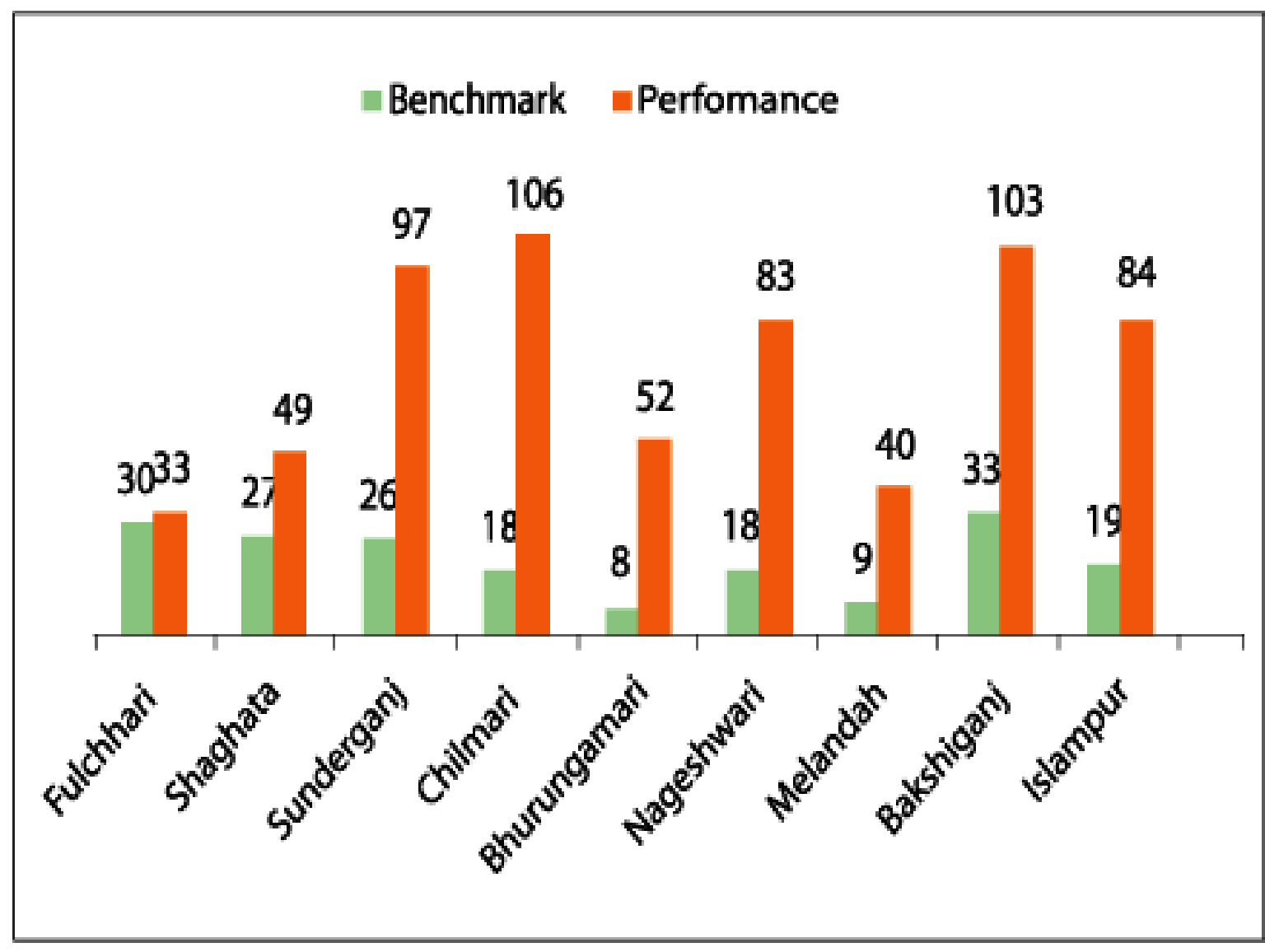

Note: "Benchmark" is quarterly average of institutional delivery for one year before intervention

"Performance" is the average of institutional delivery for five intervention quarters

Increase in the number of deliveries was lowest at Fulchhari Upazila Health Complex, followed by Shaghata Upazila Health Complex due to small catchment areas. Even with increased quantitative performance, Fulchhari, Shaghata and Melandah Upazila Health Complexes were conducting less than 50 deliveries per quarter. Bhurungamari Upazila Health Complex was conducting more than 50 deliveries in a quarter compared to only 8 deliveries performed in a quarter before the intervention (Figure 1 ), despite having small catchment areas. There is much scope for increasing utilization of delivery services from those four health facilities.

Table 2 shows the changes in quarterly performance of Upazila Health Complexes in conducting deliveries. The increase was greater for the facilities of Kurigram followed by the facilities of Jamalpur. All Upazila Health Complexes except Fulchhari multiplied the performance. Bhurungamari increased performance ten times while Chilmari and Islampur reported a seven-time increase. Overall, there has been a progressive increase in the institutional delivery over the quarters. It is worth noting that the improvement in the performance was much greater in the last two quarters compared to the first three quarters, suggestive of the further escalation in the performance if the P4P interventions continued. 
Table 2. Quarterly performance of institutional delivery by Upazila Health Complexes

\begin{tabular}{|c|c|c|c|c|c|c|c|}
\hline District & Facility & $\begin{array}{r}\text { Pre- } \\
\text { intervention } \\
\text { quarterly } \\
\text { average }\end{array}$ & Oct-Dec ‘10 & Jan-Mar '11 & Apr-Jun '11 & Jul-Sep ‘11 & Oct-Dec ' 11 * \\
\hline \multirow{3}{*}{ Gaibandha } & Fulchhari & 30 & 36 & 18 & 35 & 38 & 39 \\
\hline & Shaghata & 27 & 36 & 38 & 31 & 71 & 69 \\
\hline & Sunderganj & 26 & 57 & 68 & 99 & 110 & 153 \\
\hline \multirow{3}{*}{ Kurigram } & Chilmari & 18 & 50 & 69 & 104 & 174 & 132 \\
\hline & Bhurungamari & 8 & 8 & 33 & 60 & 75 & 83 \\
\hline & Nageshwari & 18 & 57 & 77 & 82 & 87 & 113 \\
\hline \multirow{3}{*}{ Jamalpur } & Melandah & 9 & 29 & 30 & 39 & 46 & 54 \\
\hline & Bakshiganj & 33 & 96 & 90 & 95 & 108 & 125 \\
\hline & Islampur & 19 & 47 & 60 & 100 & 82 & 131 \\
\hline
\end{tabular}

* The last performance term consisted of October and November 2011. Weights are employed to this two-month performance to make it a quarterly achievement.

Being a referral facility, District Hospitals received and managed increased number of complicated cases. Gaibandha and Kurgiram District Hospitals multiplied the performance in institutional delivery while service volume increased remarkably for Jamalpur District Hospital. Gaibandha District Hospital on an average conducted 51 deliveries in a quarter prior to P4P intervention which increased to 182 during the intervention period. Institutional delivery at Kurgiram District Hospital increased from 88 to 255 per quarter. Traditionally, Jamalpur District Hospital used to perform a large number of deliveries. Notwithstanding, due to the P4P interventions, number of institutional deliveries increased from 363 to 563 per quarter (Figure 2). On an average, Jamalpur District Hospital conducted more than six deliveries each day during intervention.

Figure 2. Changes in quarterly performance of institutional delivery at District Hospitals

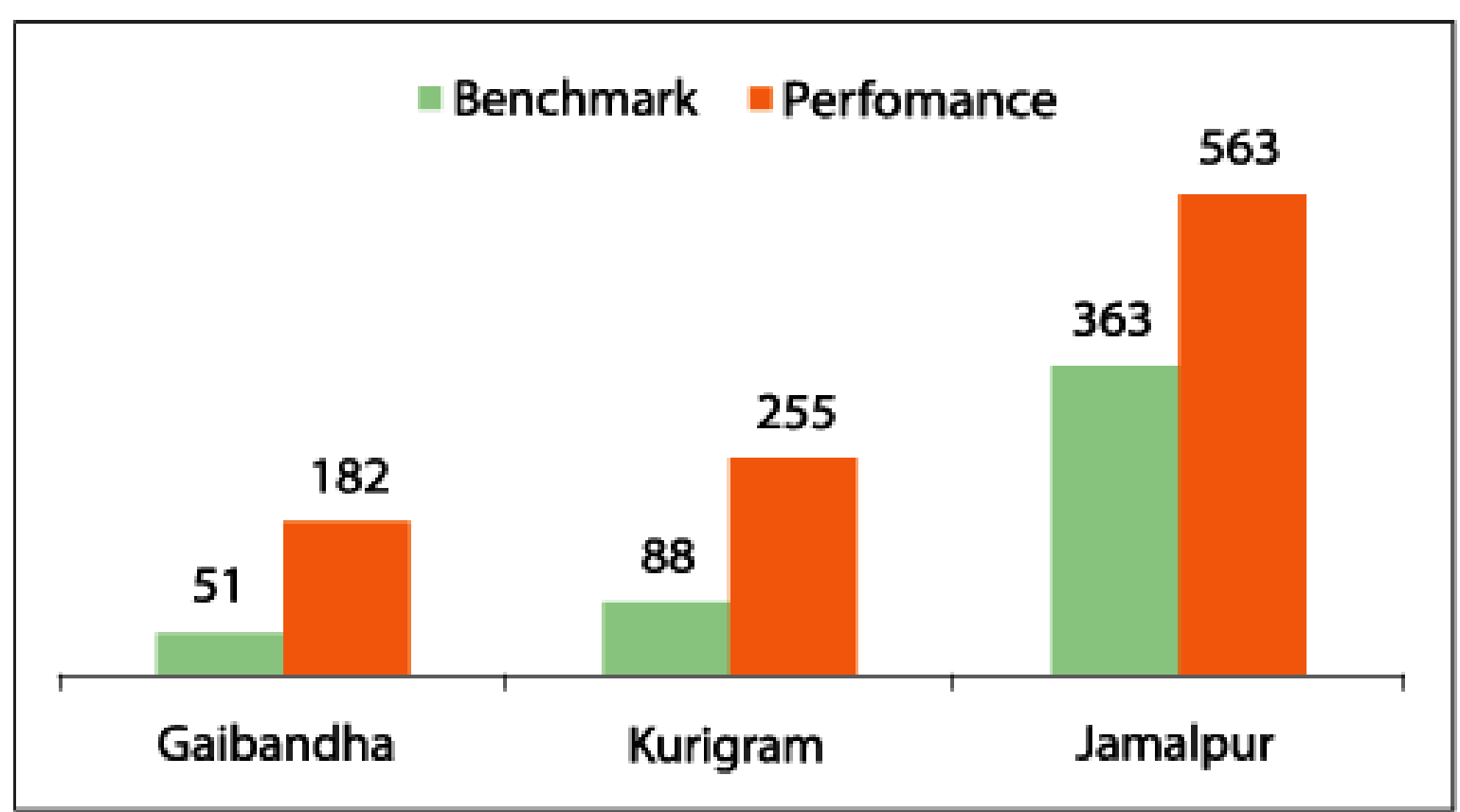

Note: "Benchmark" is quarterly average of institutional delivery for one year before intervention

"Performance" is the average of institutional delivery for five intervention quarters
It is to be noted that these District Hospitals differ in the number of beds and staff strength (Table 3). Gaibandha and Kurigram District Hospitals have 100 beds each while Jamalpur District Hospital is 250-bedded, for which the number of deliveries varied across those facilities. According to bed-doctor ratio, there is no remarkable difference between these three District Hospitals.

Table 3. Capacity of obstetric unit of District Hospitals

\begin{tabular}{lrrr}
\hline Facility & $\begin{array}{c}\text { No. of doctors } \\
\text { working in } \\
\text { Gyne/Obs unit }\end{array}$ & $\begin{array}{c}\text { Beds in } \\
\text { hospital }\end{array}$ & $\begin{array}{r}\text { Beds in } \\
\text { labor } \\
\text { ward }\end{array}$ \\
\hline Gaibandha & 3 & 100 & 10 \\
Kurigram & 4 & 100 & 10 \\
Jamalpur & 7 & 250 & 24 \\
\hline
\end{tabular}

Quarterly performance of District Hospitals in conducting deliveries during study period is presented in Table 4. Use of District Hospitals for both normal and cesarean section deliveries increased remarkably, where facilities performed more number of normal deliveries than cesarean deliveries. A stark contrast was observed for quarterly performance between normal and cesarean section deliveries over time. Gaibandha District Hospital increased normal deliveries four times while there was little increase regarding cesarean section deliveries due to limited availability of Obstetrician and Anesthesiologist pair. A reverse trend was reported by Kurigram District Hospital, where normal deliveries increased two times while cesarean section deliveries increased four times (Table 4). 
Table 4. Quarterly performance of institutional delivery by District Hospitals

\begin{tabular}{llrrrrrrr}
\hline \multirow{2}{*}{ Facility } & $\begin{array}{l}\text { Type of } \\
\text { delivery }\end{array}$ & $\begin{array}{r}\text { Pre- } \\
\text { intervention } \\
\text { quarterly } \\
\text { average }\end{array}$ & $\begin{array}{r}\text { Oct-Dec } \\
\text { '10 }\end{array}$ & $\begin{array}{r}\text { Jan-Mar } \\
\text { '11 }\end{array}$ & $\begin{array}{r}\text { Apr-Jun } \\
\text { '11 }\end{array}$ & $\begin{array}{r}\text { Jul-Sep } \\
\text { '11 }\end{array}$ & $\begin{array}{r}\text { Oct-Dec } \\
\text { '11 }\end{array}$ & $\begin{array}{r}\text { P4P } \\
\text { quarterly } \\
\text { average }\end{array}$ \\
\hline \multirow{3}{*}{ Gaibandha* } & Normal & 36 & 114 & 133 & 117 & 165 & 249 & 156 \\
& Cesarean & 15 & 18 & 28 & 20 & 25 & 39 & 26 \\
& Total & 51 & 132 & 161 & 137 & 190 & 288 & 182 \\
\hline \multirow{3}{*}{ Kurigram } & Normal & 72 & 126 & 111 & 138 & 251 & 294 & 184 \\
& Cesarean & 16 & 47 & 45 & 71 & 99 & 95 & 71 \\
& Total & 88 & 173 & 156 & 209 & 350 & 389 & 255 \\
\hline \multirow{3}{*}{ Jamalpur } & Normal & 168 & 329 & 251 & 274 & 307 & 299 & 292 \\
& Cesarean & 195 & 299 & 313 & $204 * *$ & 273 & 267 & 271 \\
& Total & 363 & 628 & 564 & 478 & 580 & 566 & 563 \\
\hline
\end{tabular}

* From October 2010 to April 2011 an anesthesiologist was arranged on call basis to provide EOC services two days a week. In May 2011, an Anesthesiology Consultant joined against the sanctioned position.

** Gyne Consultant was on training in Dhaka during April-May 2011.

Performance difference between normal and cesarean section deliveries was not large for Jamalpur District Hospital. Prior to P4P intervention, 195 cesarean section deliveries were conducted at Jamalpur District Hospital, which rose to 271 due to intervention. There was nearly similar increase concerning normal delivery (from 168 to 292 per quarter) (Table 4).

In terms of quality, facilities that have achieved performance targets used partrograph in almost all deliveries and improved the readiness of labor room, emergency room, female ward, pediatric ward, laboratory, pharmacy and store. They have also introduced the antenatal care and postnatal care corner for effective counseling and follow-up for high-risk pregnant women. Moreover, round-the-clock service provision, improved record keeping, and management of critical cases were some of the testimonies to the effective leadership and enhanced commitment of providers. Facilities were found committed in improving instruments processing through sterilization with updated register and by separating un-sterile and sterile areas as well as improving storeroom management with bin cards and updated registers. Suggestion box was installed for clients to provide feedback on the improvement of services. There was increase in bed occupancy at the facilities, which is the one of the key indicators of quality and round-the-clock availability of services.

Figure 3 presents an aggregate performance comparison within the models and control. The largest change was observed for Model 1 where the aggregate performance of eight facilities of Gaibandha and Kurigram districts was estimated. Quarterly performance increased from 33 to 107 deliveries under Model 1, with a 224 percent increase. Model 2 has been credited with 86 percent increase where four facilities of Jamalpur performed 197 deliveries per quarter during intervention compared to 106 before intervention. On the other hand, non-exposure to P4P intervention did not yield any noticeable improvement for the control district. Four facilities of Thakurgaon conducted 213 deliveries altogether, which slightly increased to 234 per quarter, with only 10 percent increase.

Figure 3. Changes in institutional delivery across intervention and control sites

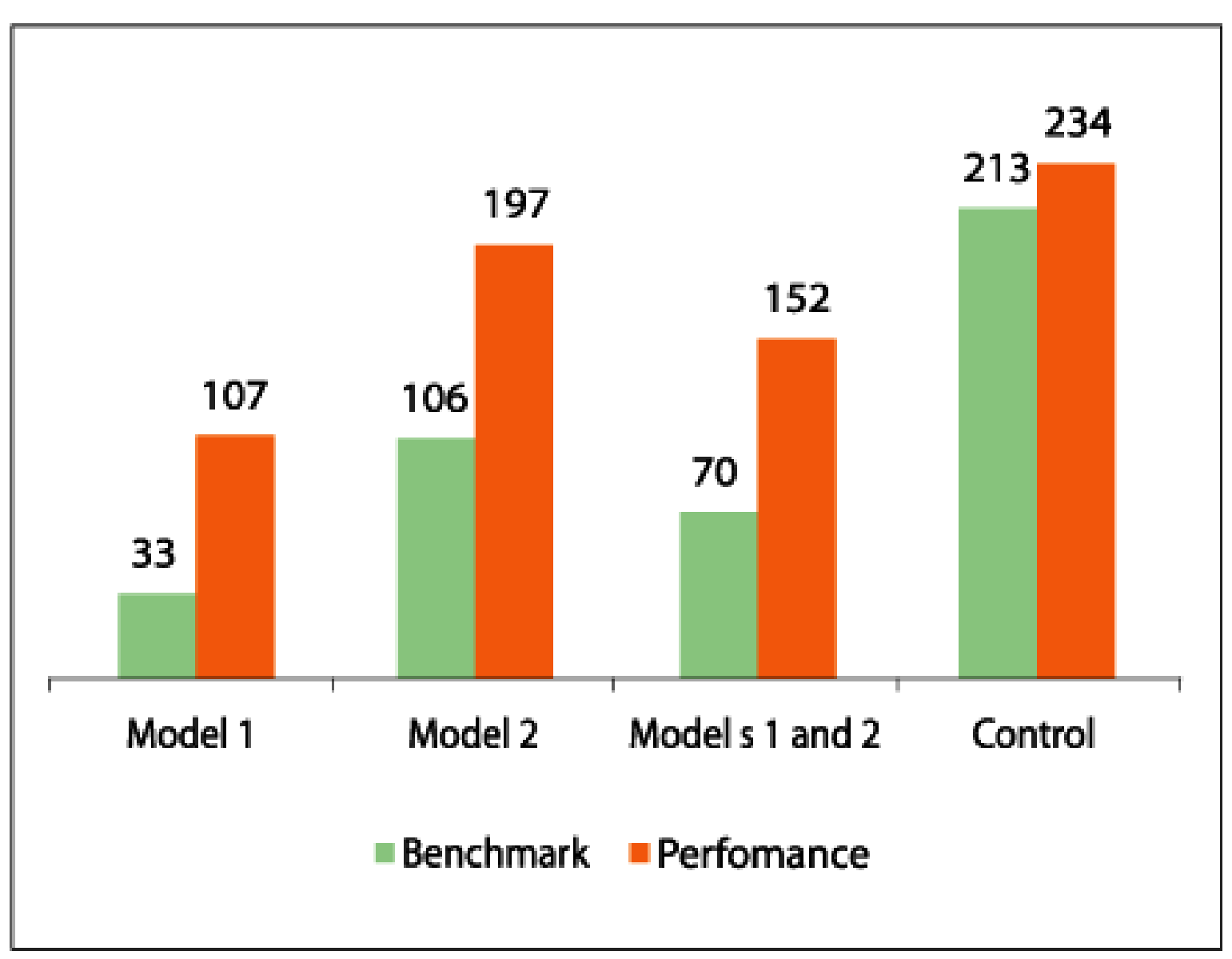




\section{LESSONS LEARNED}

Study findings demonstrate that incentive has the potential to entice the service providers to perform to reach the target within the stipulated time. Despite shortage of human resources, all facilities improved the performance on institutional delivery. Facilities responded to the performance targets in terms of increasing quantity and quality of $\mathrm{MNCH}$ services. Evidently, performance-based incentives motivated additional efforts. The following are several key lessons learned from the P4P project.

- Providing incentives to motivate service providers at the institution level instead at the individual level is a unique characteristic of the P4P study. Performance-based incentive to management, service, administrative and support staff based on their level of efforts contributed to ensure teamwork as a way to improve outcomes.

- Linking provider performance with both quantity and quality of services is another useful innovation for impacting the overall improvement of service delivery.

- P4P project is noted for introducing quality assurance mechanism in the health system. This quality assurance system helped in identifying gaps in service delivery, ensuring regularity of services, providing mentoring on a regular basis, and encouraging compliance with recommended clinical practice. Quality assurance mechanism to improve $\mathrm{MNCH}$ services tested under the P4P scheme can be employed for improving the monitoring of health service delivery in Bangladesh.

- Under P4P project, unit-based "quality assurance teams" assessed their own performance every two weeks and facility managers monitored once a month and addressed barriers. Accountability of the providers can be increased through quality assurance teams within the facility.

The major challenge confronted during the project period was that within the district, some Upazila Health Complexes had required staff-mix while others

had acute shortages of doctors. Central recruitment or distribution of human resources is a long-term process. As an interim measure, Civil Surgeon should be allowed to rearrange the workforce across Upazila Health Complexes, so that each of them will have minimum required staff-mix. Highest importance should be given to ensure pair (Obstetrician and Anesthesiologist) at the facility.

The key limitation of this study is that the P4P interventions were tested at the upazila level and above. Exclusion of facilities at the union level, i.e. Health and Family Welfare Centers (HFWCs), from the P4P study was a key barrier to refer clients from union to upazila and district level hospitals. A whole district approach, incorporating all upazilas of a district with both upazila- and union-level facilities, should be adopted in future.

P4P interventions were implemented for only 14 months. This was not sufficient to generate expected improvement in the historically low institutional delivery. Notwithstanding, there was incremental, progressive increase in the institutional delivery during the project period which suggests further increase if such incentives continue. Future endeavors on performance-based incentives should spread over a longer duration.

\section{WAY FORWARD}

Performance-based incentive mechanism is an effective strategy to tackle issues related to service use and provider performance. P4P study has shown promises in rapidly increasing institutional delivery. In Bangladesh, the need for implementing performance-based financing programs to meet MDGs and other health indicators is beyond argument. Specifically, such encouragement is required until certain level of institutional deliveries and improvement in maternal and child health are reached.

This policy brief was prepared by

Md. Noorunnabi Talukder, Ubaidur Rob,

Laila Rahman, Ismat Ara Hena, and

A.K.M. Zafar Ullah Khan.

The Population Council confronts critical health and development issues-from stopping the spread of HIV to improving reproductive health and ensuring that young people lead full and productive lives. Through biomedical, social science and public health research in about 50 countries, the Council works with our partners to deliver solutions that lead to more effective policies, programs, and technologies to improve lives worldwide. Established in 1952 and headquartered in New York, the Council is a nongovernmental, nonprofit organization with an international board of trustees. 